EDITORIAL REPORTS

\title{
Preface
}

\section{Hadi Nasseri}

(C) Springer-Verlag Berlin Heidelberg and Fuzzy Information and Engineering Branch of the Operations Research Society of China

2011

International Conference on Fuzzy Information and Engineering (ICFIE) is an event which is launched by the Fuzzy Information and Engineering Branch of the Operation Research Society of China (FIEBORSC) every two year. After the Second ICFIE held in Guangzhou, China, May 13-16, 2007, I became familiar to Prof. Bing-yuan Cao and then I invited him to attend the 2nd International Conference of Iranian Operations Research Society (ICIORS) which was held in Babolsar, Iran, 20-22 May, 2009 as invited speaker to present his talk entitled "Fuzzy Geometric Programming” . After that, I suggested, to Prof. Cao, hosting the 4th ICFIE in Iran with cooperation of two Iranian societies: 1) Iranian Fuzzy System Society and 2) Iranian Operations Research Society. Based on our agreement and determination of the international committee members, the 4th International Conference on Fuzzy Information and Engineering was held in Amol, Iran, October 14-15, 2010. Keynotes was addressed by Prof. Eyke Hullermeier (University of Marburg, Germany), Prof. Bing-yuan Cao (Guangzhou University, China) and Prof. Reza Ameri (University of Mazandaran, Iran).

The conference received more than 350 submissions and the scientific committee accepted 154 papers for oral presentation. A number of them were considered for possible inclusion in this Special Issue (SI). After careful referee, 8 papers selected to appear in the SI.

On behalf of the International Scientific Committee, I greatly appreciate the Scientific Committee Chairman, Dr Javad Vahidi, and his colleagues of Shomal University for host, and Fuzzy Information and Engineering Branch of the Operation Research Society of China and Iranian Operations Research and Iranian Fuzzy System Societies for their cooperation and supports. Also I wish to gratefully acknowledge all

Hadi Nasseri $(\otimes)$

Department of Mathematics, University of Mazandaran, Babolsar, Iran

On behalf of the International Scientific Committee for ICFIE'2010, Shomal University, Iran

email: nasseri@umz.ac.ir 
those who have generously given their time to referee the papers submitted to the SI of Journal of Fuzzy Information and Engineering. Finally, I specially thank to Prof. Bing-yuan Cao for helping to publish this special issue in Fuzzy Information and Engineering. 